\title{
Effects of icariin on cell injury and glucocorticoid resistance in BEAS-2B cells exposed to cigarette smoke extract
}

\author{
LINGLI HU ${ }^{1,2^{*}}$, FENG LIU $^{1,2^{*}}$, LULU LI $^{1,2}$, LI ZHANG $^{3}$, CHEN YAN $^{1,2}$, QIUPING LI $^{1,2}$, \\ JIAN QIU $^{1,2}$, JINGCHENG DONG $^{1,2}$, JING SUN $^{1,2}$ and HONGYING ZHANG ${ }^{1,2}$ \\ ${ }^{1}$ Department of Integrative Medicine; ${ }^{2}$ Institute of Integrated Traditional Chinese and Western Medicine; \\ ${ }^{3}$ Department of Rehabilitation, Huashan Hospital, Fudan University, Shanghai 200040, P.R. China
}

Received June 6, 2019; Accepted February 11, 2020

DOI: $10.3892 / \mathrm{etm} .2020 .8702$

\begin{abstract}
Glucocorticoids (GCs) exert a therapeutic effect in numerous chronic inflammatory diseases. However, chronic obstructive pulmonary disease (COPD) tends to be $\mathrm{GC}$-resistant. Icariin, a major component of flavonoids isolated from Epimedium brevicornum Maxim (Berberidaceae), significantly relieves symptoms in patients with COPD. However, the mechanism of action remains unclear and further investigation is required to establish whether it may serve as an alternative or complementary therapy for COPD. The aim of the present study was to determine the effects of icariin in human bronchial epithelial cells exposed to cigarette smoke extract (CSE) and to determine whether icariin reverses GC resistance. The results revealed that icariin significantly increased the proliferation of CSE-exposed cells. Furthermore, icariin significantly increased protein expression of the anti-inflammatory factor interleukin (IL)-10 and significantly decreased protein expression of the pro-inflammatory factors IL- 8 and tumor necrosis factor $\alpha$. Icariin also attenuated the expression of the cellular matrix remodelling biomarkers matrix metallopeptidase 9 and tissue inhibitor of metalloproteinase 1, and decreased the production of reactive oxygen species (ROS). In addition, icariin regulated the expression of GC resistance-related factors, such as GC receptors, histone deacetylase 2, nuclear factor erythroid-2-related factor 2 and nuclear factor $\kappa \mathrm{B}$. The results obtained in the present study suggested that icariin may decrease CSE-induced inflammation, airway remodelling and
\end{abstract}

Correspondence to: Dr Jing Sun or Dr Hongying Zhang, Department of Integrative Medicine, Huashan Hospital, Fudan University, 3rd Floor, Building 6, 12 Urumqi Middle Road, Jing'an, Shanghai 200040, P.R. China

E-mail: sjing0610@163.com

E-mail: zhy3049@163.com

*Contributed equally

Key words: icariin, chronic obstructive pulmonary disease, cigarette smoke extract, inflammation, airway remodelling, reactive oxygen species, glucocorticoid resistance
ROS production by mitigating GC resistance. In conclusion, icariin may potentially be used in combination with GCs to increase therapeutic efficacy and reduce GC resistance in COPD.

\section{Introduction}

Chronic obstructive pulmonary disease (COPD) is predicted to be the fourth leading cause of death worldwide by 2030 , accounting for $5 \%$ of global mortalities (1-3). The disease is characterized by an imbalance in proinflammatory and anti-inflammatory factors, airway remodelling and an increased production of reactive oxygen species (ROS). Cigarette smoke, the primary cause of COPD, contains $>7,000$ chemicals that cause bronchial epithelium damage, inflammatory cells infiltration and tissue remodelling (4,5). Furthermore, a previous study revealed that prolonged exposure to cigarette smoke resulted in irreversible epithelial cell damage that increased the production of pro-inflammatory chemokines and ROS, and induced apoptosis (6). The increased production of the pro-inflammatory chemokines interleukin (IL)-8 and tumor necrosis factor $\alpha$ (TNF- $\alpha$ ), the remodelling biomarkers matrix metallopeptidase 9 (MMP9) and tissue inhibitor of metalloproteinase 1 (TIMP1), and ROS have been associated with the severity of COPD (7-9).

Glucocorticoids (GCs) are used to treat numerous chronic inflammatory diseases, such as asthma $(10,11)$, rheumatoid arthritis (12) and inflammatory bowel disease (13-15). GCs reverse histone acetylation by binding with glucocorticoid receptors (GR) and recruiting histone deacetylase 2 (HDAC2) to the activated transcription complex. At higher GC concentrations, the GC-GR complex acts on the DNA recognition site to facilitate gene transcription by enhancing histone acetylation (16). However, decreased GC sensitivity has been reported in patients with COPD (17-21) and in vitro and in vivo studies have provided evidence for GC resistance in COPD (20-23). Reversing GC resistance in COPD remains a clinical challenge and novel therapeutic agents are required.

In the clinical treatment of COPD with traditional Chinese medicine, several patients have noted symptom improvement following administration of Epimedium brevicornum Maxim, the active ingredient of which is icariin $(24,25)$. Icariin has been shown to exert anti-remodelling, anticancer and 
cardiovascular protective effects, as well as to promote bone formation (26-29). Additionally, icariin exhibited anti-inflammatory and antioxidant effects in cigarette smoke-induced inflammatory models in vivo and in vitro, possibly by suppressing NF- $\mathrm{KB}$ activation and altering the production of nitrous oxide, nitric oxide synthase, superoxide dismutase and $\mathrm{T}$ lymphocytes (30-32).

The present study hypothesized that icariin could alleviate cell injury in human bronchial epithelial cells (BEAS-2B) exposed to cigarette smoke extract (CSE) by modulating remodelling-related factors and restoring the balance of pro-inflammatory and anti-inflammatory factors. Furthermore, the present study investigated whether icariin reversed GC resistance.

\section{Materials and methods}

BEAS-2B cell culture. Human BEAS-2B cells (American Type Tissue Collection) were plated in six-well plates at a density of $1.5-2 \times 10^{6}$ cells/well, cultured in complete BEAS-2B culture medium (BEBM) and incubated at $37^{\circ} \mathrm{C}, 5 \% \mathrm{CO}_{2}$. Complete BEBM was formulated by supplementing BEBM basal medium (Lonza Group Ltd.) with a BEGM SingleQuots kit (Lonza Group Ltd.), which consisted of bovine pituitary extract, hydrocortisone, human epidermal growth factor, epinephrine, transferrin, insulin, retinoic acid, triiodothyronine, gentamicin and amphotericin-B.

CSE preparation and BEAS-2B cell exposure. An unfiltered cigarette was combusted with the use of a peristaltic pump. Cigarette smoke was slowly bubbled into $5 \mathrm{ml}$ complete BEBM from the start of the ignition to the end of the cigarette burnout, which took $\sim 5 \mathrm{~min}$. The resulting medium was adjusted to $\mathrm{pH} 7.4$, sterile-filtered through a $0.22-\mu \mathrm{m}$ Millex filter (EMD Millipore) and defined as $100 \%$ CSE. BEAS-2B cells were pre-treated with 20,40 and $80 \mu \mathrm{M}$ icariin (Shanghai Ronghe Corporation) and $10 \mu \mathrm{M}$ dexamethasone (DEX; Sigma-Aldrich, Merck KGaA), or vehicle control for $24 \mathrm{~h}$ prior to exposure to $5 \% \mathrm{CSE}$ for $4 \mathrm{~h}$ at $37^{\circ} \mathrm{C}, 5 \% \mathrm{CO}_{2}$ (32). The vehicle used was DMSO (Sigma-Aldrich; Merck KGaA). The applied concentration of DMSO in both control and treated groups was $1.6 \mu 1 / \mathrm{ml}$, lower than the cytotoxic concentration (33). The morphological changes to BEAS-2B cells were visualised using a Zeiss AxioVert A1 fluorescence microscope (Carl Zeiss AG) at low power (x10 magnification).

Cell proliferation assay. A total of $100 \mu 1$ BEAS-2B cell suspension $\left(1 \times 10^{4}\right.$ cells $\left./ \mathrm{ml}\right)$ was plated per well in a $96-$ well plate and cultured in complete BEBM overnight at $37^{\circ} \mathrm{C}$, $5 \% \mathrm{CO}_{2}$. Cell proliferation was determined using the Cell Counting Kit-8 (CCK-8; Dojindo Molecular Technologies, Inc.) according to the manufacturer's protocol. The absorbance was measured at $450 \mathrm{~nm}$ using a plate reader (TECAN Infinite 200 PRO; Tecan Group, Ltd.).

Western blotting. Cellular proteins were extracted from the BEAS-2B cells using a nuclear and cytoplasmic protein extraction kit (Beyotime Institute of Biotechnology) according to the manufacturer's protocol and phenylmethylsulfonyl fluoride. Total protein concentration was determined using an enhanced bicinchoninic acid protein assay kit (Beyotime Institute of Biotechnology). Western blotting was subsequently performed as previously described (34). The following primary antibodies were used in the present study: Anti-GR (Santa Cruz Biotechnology, Inc.; cat. no. sc-393232; 1:1,000), anti-HDAC2 (Cell Signaling Technology, Inc.; cat. no. 2540; 1:2,000), anti-NF- $\mathrm{BB}$ (Cell Signaling Technology, Inc.; cat. no. 4764; 1:1,000) and anti-GAPDH (Cell Signaling Technology, Inc.; cat. no. 5174; 1:5,000). Following primary antibody incubation, the membranes were incubated with a horseradish peroxidase-labelled secondary antibody (Santa Cruz Biotechnology, Inc.; cat. no. 2357; 1:50,000). Band intensities were quantified using ImageJ analysis software (Version: 1.52t; National Institutes of Health), with GAPDH as the loading control. All western blot experiments were performed in triplicates.

ELISA analysis of IL-8,IL-10,TNF- $\alpha, M M P 9$ and TIMP1 concentrations in BEAS- $2 B$ cell culture medium. The concentrations of IL-8 (Boatman Biotech, Co., Ltd.; cat. no. ETA05989), IL-10 (Shanghai ExCell Biology, Inc.; cat. no. EM005), TNF- $\alpha$ (Shanghai ExCell Biology, Inc; cat. no. EM008), MMP9 (R\&D Systems, Inc.; cat. no. MMPT90), TIMP1 (R\&D Systems, Inc.; cat. no. MTM100) in BEAS-2B cell culture medium were quantified using ELISA kits (names, catalogue number and supplier listed previously) according to the manufacturer's protocol.

Immunofluorescence staining. The expression of nuclear factor erythroid-2-related factor 2 (Nrf2) in BEAS-2B cells was analysed using immunofluorescence staining. Complete BEBM was removed and the cells were washed using phosphate-buffered saline (PBS). The cells were subsequently fixed using ice cold $4 \%$ paraformaldehyde for $15 \mathrm{~min}$ at room temperature. The cells were washed 3 times in PBS for 5 min each. The cells were then blocked using Blocking Buffer (1x PBS/5\% normal goat serum; cat. no. ab7481; Abcam)/0.3\% Triton X-100 (cat. no. T8787; Sigma Aldrich, Merck KGaA;) for $60 \mathrm{~min}$ at room temperature. The cells were washed again and incubated with a primary antibody against Nrf2 (Sigma-Aldrich, Merck $\mathrm{KGaA}$; cat. no. SAB4501984) overnight at $4^{\circ} \mathrm{C}$. The following day, the cells were washed 4 times, 10 min each time, with PBS and incubated with a donkey-anti-rabbit secondary antibody (Thermo Fisher Scientific, Inc.; cat. no. A-21207; 1:200) for $1.5 \mathrm{~h}$ at room temperature. The cells were subsequently counterstained with the nuclear stain DAPI (Sigma-Aldrich, Merck KGaA; $0.6 \mathrm{mM}$ in PBS) for $4 \mathrm{~min}$ at room temperature. Stained cells were imaged using a Zeiss AxioVert A1 fluorescence microscope (Carl Zeiss AG; x40 magnification). A total of 6 fields were analysed.

Reverse transcription-quantitative PCR (RT- $q P C R)$. Total RNA was extracted from BEAS-2B cells using TRIzol ${ }^{\mathrm{TM}}$ reagent (Takara Bio, Inc.) following the manufacturer's protocol. Total RNA was reverse transcribed into cDNA using the iScriptDNA Synthesis kit (Bio-Rad Laboratories, Inc.; cat. no. 1708891) using the following temperature protocol: Priming at $25^{\circ} \mathrm{C}$ for $5 \mathrm{~min}$, RT at $46^{\circ} \mathrm{C}$ for $20 \mathrm{~min}$, reverse transcriptase inactivation at $95^{\circ} \mathrm{C}$ for $1 \mathrm{~min}$, and then holding at $4^{\circ} \mathrm{C}$. A total of $1 \mathrm{ml}$ cDNA was subjected to qPCR using 
Power SYBR Green PCR Master mix (Applied Biosystems, Thermo Fisher Scientific, Inc.; cat. no. A25742) and the ABI 6500 fast Real-Time PCR system (Applied Biosystems; Thermo Fisher Scientific, Inc.). The thermocycling conditions of the qPCR steps were as follows: Activation (temperature: $50^{\circ} \mathrm{C}$; duration: 2 min; cycles: hold), Dual-LockTM DNA polymerase (temperature: $95^{\circ} \mathrm{C}$; duration: $2 \mathrm{~min}$; cycles: hold), denaturation (temperature: $95^{\circ} \mathrm{C}$; duration: $15 \mathrm{sec}$; cycles: 40 ) and annealing/extension (temperature: $60^{\circ} \mathrm{C}$; duration: $1 \mathrm{~min}$; cycles: 40). The following primers were used for qPCR: GR forward, 5'-GGACCACCTCCCAAACTCTG-3' and reverse, 5'-GCTGTCCTTCCACTGCTCTT-3'; HDAC2 forward, 5'-CCATGGCGTACAGTCAAGGA3-' and reverse, 5'-TCA TTTCTTCGGCAGTGGCT-3'; GAPDH forward, 5'-AGA AGGCTGGGGCTCATTTG-3' and reverse, 5'-AGGGGC CATCCACAGTCTTC-3'; NF- $\kappa$ B forward, 5'-CTGTCCTTT CTCATCCCATCTT-3' and reverse, 5'-TCCTCTTTCTGC ACCTTGTC-3'; and IL-8 forward, 5'-TGGATTTCCCCC TTGCAACC-3' and reverse, 5'AAATCCTGACTGGGTCGC TG3'. The relative expression level of each gene was determined against the GAPDH level in the same sample. The fold-change of the target genes was calculated by using the $2^{-\Delta \Delta \mathrm{Cq}}$ method (35).

Cellular ROS analysis. ROS levels in BEAS-2B cell were detected using a human intracellular ROS assay kit (Nanjing Jiancheng Bioengineering Institute, Co., Ltd.) according to manufacturer's instructions. Flow cytometry was also used to detect the levels of ROS in BEAS-2B cells. BEAS-2B cells $\left(0.5-1 \times 10^{6}\right.$ cells/sample) were incubated with dihydrogenrhodamine 123 (Sigma-Aldrich, Merck KGaA) for $1 \mathrm{~h}$ at $37^{\circ} \mathrm{C}$ and the fluorescence intensity of cellular oxidized rhodamine 123 was detected using a flow cytometer (Attune NxT; Thermo Fisher Scientific, Inc.) and analysed using using Attune NxT Software (version 2.6; Thermo Fisher Scientific, Inc.).

Statistical analysis. Data are presented as the mean \pm standard deviation). All experiments were performed in duplicates at least three separate times. The western blotting and immunofluorescence staining experiments were performed three times. Statistical analyses were performed using GraphPad Prism software (version 6.02; GraphPad Software, Inc.). The one-way ANOVA followed by the Tukey's post hoc test was used to analyze the differences among multiple groups. $\mathrm{P}<0.05$ was considered to indicate a statistically significant difference.

\section{Results}

Icariin increases the proliferation of $B E A S-2 B$ cells exposed to CSE. BEAS-2B cells exposed to CSE for $4 \mathrm{~h}$ exhibited morphological changes, including retracted processes and flattening and enlargement of cell bodies. These morphological changes were less prominent in BEAS-2B cells treated with 20,40 and $80 \mu \mathrm{M}$ icariin. The CCK-8 assay was used to determine the effect of icariin on the proliferation of BEAS-2B cells exposed to CSE. The proliferation of CSE-exposed BEAS-2B cells was significantly reduced compared with the control group. Following treatment with icariin, the proliferation of BEAS-2B cells increased in a dose-dependent manner. Furthermore, cells treated with $80 \mu \mathrm{mol} / 1$ icariin exhibited increased proliferation beyond the positive control group (DEX; Fig. 1A-B).

Icariin balances the secretion of pro-inflammatory and anti-inflammatory cytokines in BEAS-2B cells exposed to $C S E$. The levels of the pro-inflammatory cytokines IL-8 and TNF- $\alpha$ in the BEAS-2B cell culture medium were quantified using ELISA and RT-qPCR. The results revealed that the expression of IL- 8 and TNF- $\alpha$ increased in response to CSE exposure. However, icariin exposure resulted in a significant reduction in this expression as evidenced by protein (Fig. 2A and B) and mRNA (Fig. 2C) levels of IL-8. Additionally, exposure significantly increased the expression of the anti-inflammatory cytokine IL-10 (Fig. 2D). Moreover, 40 and $80 \mu \mathrm{M}$ icariin were superior to DEX for the regulation of the pro-inflammatory and anti-inflammatory balance. Collectively, the data suggested that icariin may play a role in reducing CSE-induced cell injury by balancing the secretion of pro-inflammatory and anti-inflammatory cytokines.

Icariin protects cells from damage caused by the CSE-induced secretion of ROS and remodelling-related factors. The level of ROS and DHR123 were significantly increased in response to CSE exposure in BEAS-2B cells. Icariin $(80 \mu \mathrm{M})$ inhibited ROS and DHR 123 expression to a similar extent as DEX (Fig. 3A-C). These data suggested that icariin may attenuate oxidative damage in cells induced by CSE.

MMP9 is associated with numerous pathological processes, including remodelling of the respiratory tract (36). TIMP1, a multi-functional protein, is an inhibitory molecule that alters cell viability and regulates MMPs and cell-matrix renewal (37). CSE significantly increased the levels of MMP9 and TIMP1 in the BEAS-2B cell culture medium (Fig. 3D and E). However, icariin treatment decreased the levels of MMP9 and TIMP1, which may partially explain its anti-remodelling effect.

Icariin attenuates $C S E$-induced $G C$ resistance. Due to primary GC resistance in COPD, GCs are unable to effectively inhibit the inflammatory response. Studies have shown that the factors associated with GC resistance include HDAC2, Nrf2 and $\mathrm{NF}-\kappa \mathrm{B}(23,38,39)$. The present study revealed that $\mathrm{CSE}$ significantly decreased the protein and mRNA expression levels of GR, Nrf2 and HDAC2 and increased the protein and mRNA levels of NF- $\kappa \mathrm{B}$. However, icariin treatment reversed these changes (Figs. 4A-F and S1A-D). Collectively, the results suggested that icariin exerted a positive effect on $\mathrm{GC}$ resistance.

\section{Discussion}

The results of the present study revealed that icariin significantly increased cell proliferation, regulated the release of pro-inflammatory and anti-inflammatory factors, inhibited ROS generation and decreased remodelling factor secretion in an experimental model of CSE-exposed BEAS-2B cells. The protective effects exhibited may be associated with the reversal of GC resistance, increasing the levels of Nrf2, GR and HDAC2 and decreasing $\mathrm{NF}-\kappa \mathrm{B}$ expression. These data support the unique therapeutic value of icariin in the treatment of COPD. 

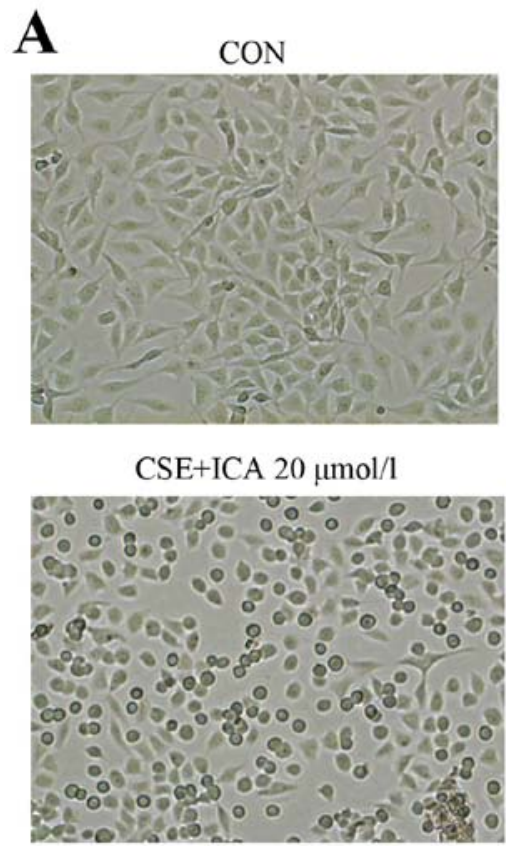

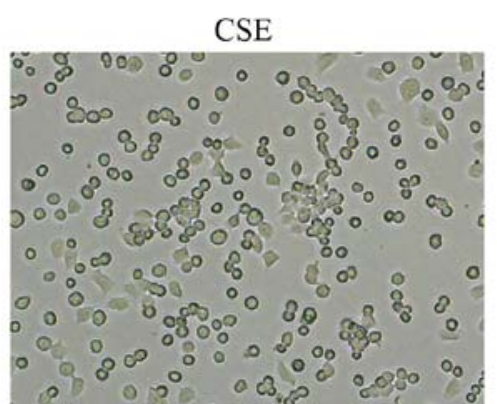

$\mathrm{CSE}+\mathrm{ICA} 40 \mu \mathrm{mol} / 1$

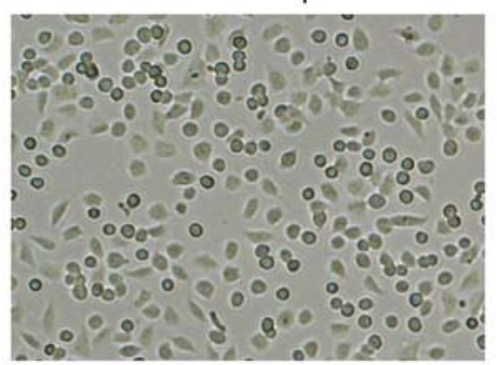

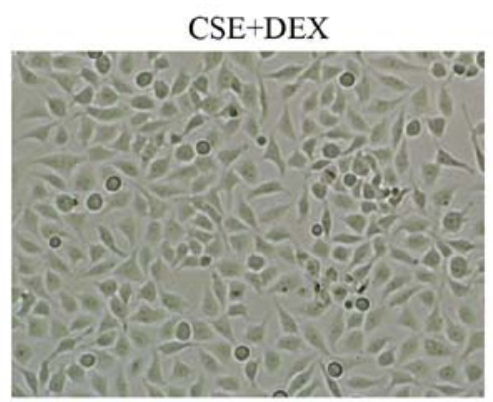

$\mathrm{CSE}+\mathrm{ICA} 80 \mu \mathrm{mol} / \mathrm{l}$

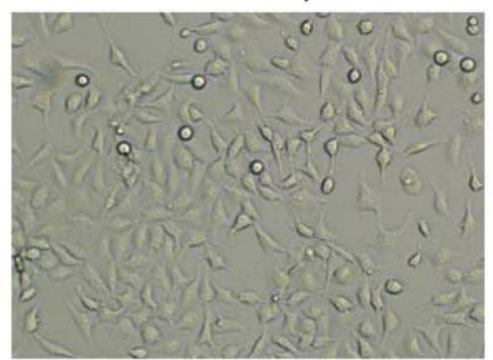

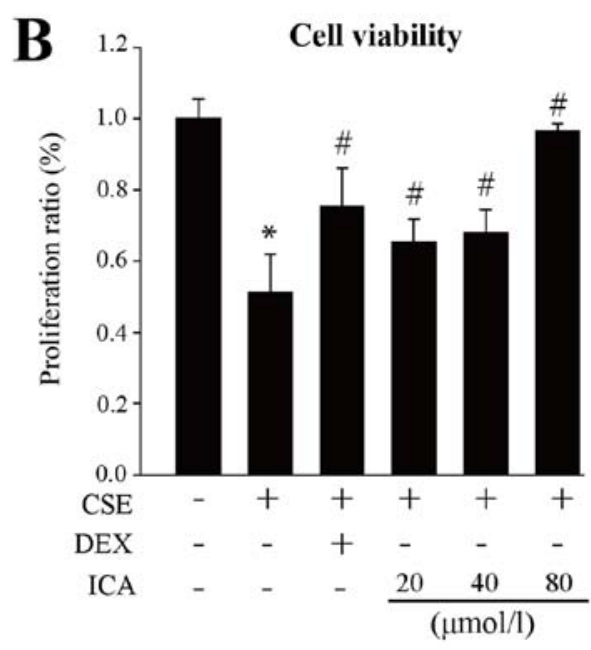

Figure 1. Effects of icariin on CSE-induced cytotoxicity in BEAS-2B cells. The cells were pre-treated with 20, 40 and $80 \mu \mathrm{M}$ icariin, $10 \mu \mathrm{M}$ DEX or vehicle for $24 \mathrm{~h}$, then treated with 5\% CSE for $4 \mathrm{~h}$. (A) Representative micrographs of each group of cells. The morphological changes were visualised using a Zeiss AxioVert A1 fluorescence microscope (Carl Zeiss AG) at low power (x10 magnification). (B) A Cell Counting Kit-8 assay was used to determine cell proliferation. Data are expressed as the mean \pm standard deviation $(n=6)$. ${ }^{*} \mathrm{P}<0.05$ vs. vehicle and ${ }^{\#} \mathrm{P}<0.05$ vs. CSE. CON, control; CSE, cigarette smoke extract; DEX, dexamethasone; ICA, icariin.

Cigarette smoke contains thousands of toxic chemicals and carcinogens and is regarded as a leading risk factor for COPD, in which cigarette smoke triggers inflammatory responses, induces the production of endogenous ROS and increases the expression of remodelling-related factors (40-45). The airway epithelium is the first barrier against environmental insults such as cigarette smoke (46-48). A previous study revealed that CSE decreases the cell viability of mouse lung epithelial cells (49). In the present study, the human bronchial epithelial cell line BEAS-2B was exposed to CSE and the protective effects of icariin on cell injury and proliferation were investigated. The CCK- 8 assay demonstrated that CSE decreased the proliferation of BEAS-2B cells and icariin reversed this effect to a similar extent to DEX, which indicated that icariin may protect against CSE-induced cell injury.
COPD is a chronic non-specific disease in which inflammation of the airways activates inflammatory epithelial and smooth muscle cells and the release of inflammatory mediators such as pro-inflammatory cytokines IL- 8 and TNF- $\alpha$, and the anti-inflammatory cytokine IL-10 (50). In patients with COPD, clinical studies revealed that airway epithelial cells have higher baseline levels of IL- 8 and TNF- $\alpha$ expression and are correlated with the prognosis and severity of disease (51-54). Additionally, the specific inhibitors of IL-8 may alter the progressive course of the disease (55). Acute exacerbations of the disease may be due to increased mucus secretion as a result of increased expression of mucin genes stimulated by high levels of IL-8 (7,56). TNF- $\alpha$ also has an important role in the pathogenesis of COPD. TNF- $\alpha$ up-regulated the expression of adhesion molecules causing a large influx of inflammatory cells, and increased the production 
A
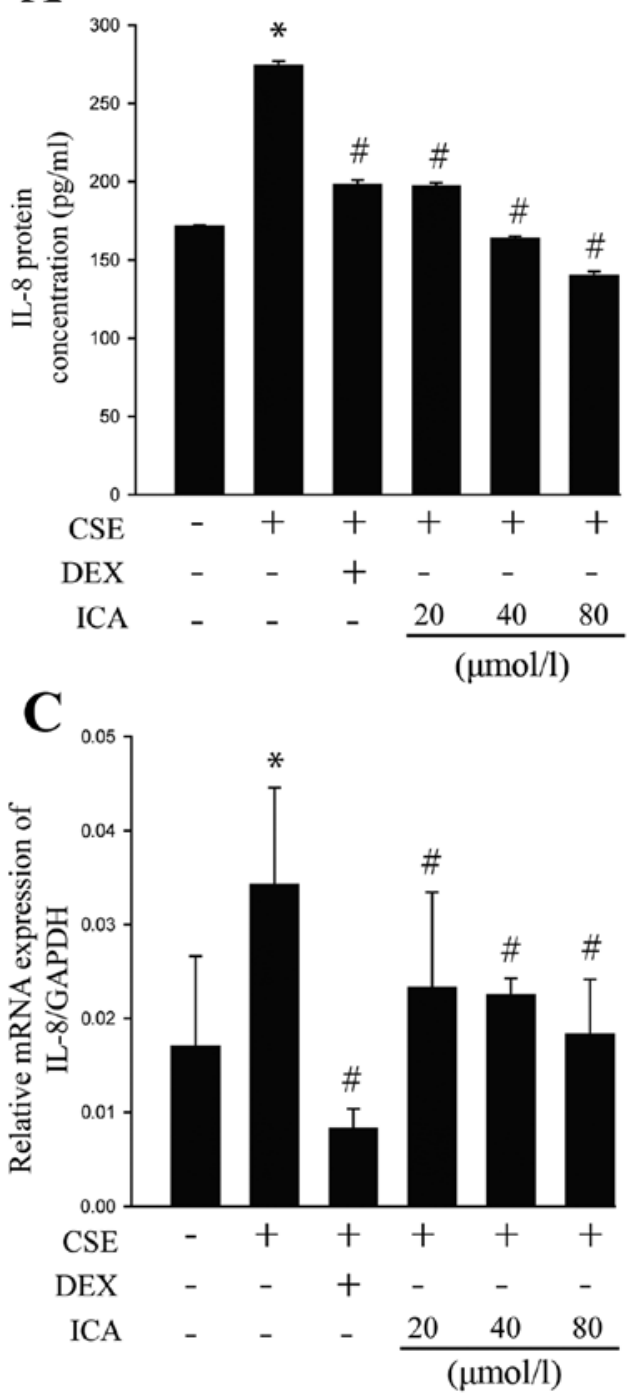

B

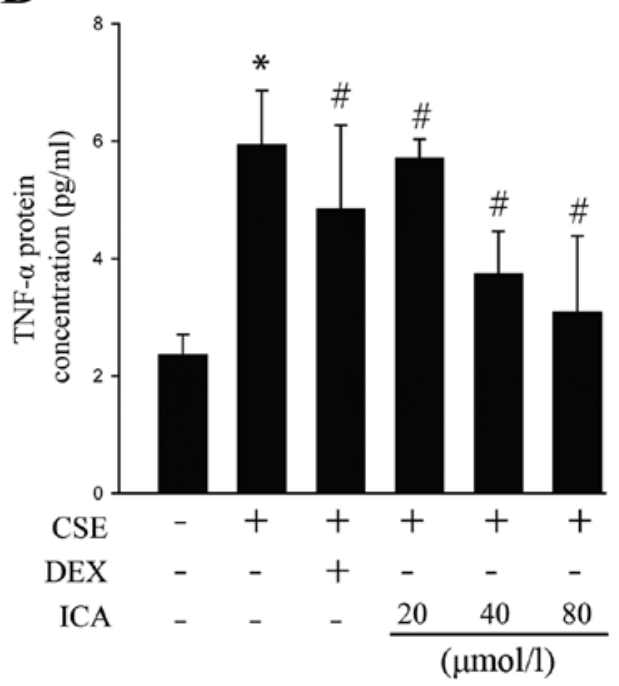

D

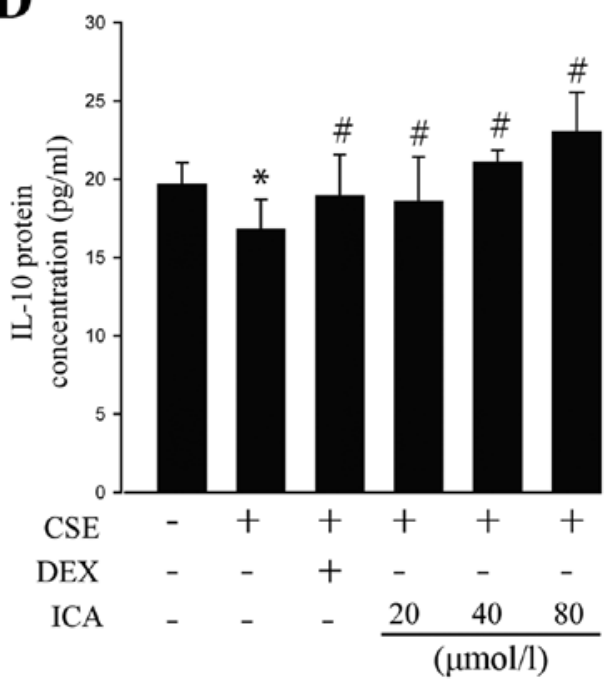

Figure 2. Role of icariin in the secretion of pro-inflammatory and anti-inflammatory cytokines in CSE-treated BEAS-2B cells. BEAS-2B cells were pre-treated with 20, 40 and $80 \mu \mathrm{M}$ icariin, $10 \mu \mathrm{M}$ DEX or vehicle for $24 \mathrm{~h}$, then treated with $5 \%$ CSE for $4 \mathrm{~h}$. ELISA measurement of (A) IL- 8 and (B) TNF- $\alpha$ in BEAS-2B cell culture medium. (C) IL-8 mRNA expression was determined by reverse transcription-quantitative PCR. (D) ELISA measurement of IL-10 in BEAS-2B cell culture medium. Data are expressed as the mean \pm standard deviation $(n=6)$. ${ }^{*} \mathrm{P}<0.05$ vs. vehicle and ${ }^{\#} \mathrm{P}<0.05$ vs. CSE. CSE, cigarette smoke extract; $\mathrm{DEX}$, dexamethasone; ICA, icariin; IL, interleukin.

of matrix metalloproteinases and tenascin promoting tissue damage and remodelling (57). IL-10 has also been implicated in the development of COPD and its secretion is affected by COPD progression and cigarette smoke (58). As an anti-inflammatory factor, IL-10 expression levels in sputum and serum were lower in patients with COPD and smokers compared with healthy controls (59). A previous study revealed that IL-10 was positively correlated and IL- 8 and TNF- $\alpha$ were negatively correlated with the forced expiratory volume in one second (FEV1), FEV1/predicted value ratio and FEV1/forced vital capacity. Plasma levels of the inflammatory cytokines IL-8, IL-10 and TNF- $\alpha$ are related to the severity of airway diseases and may serve as prognostic biomarkers for COPD (7). The results obtained in the present study revealed that icariin prevented the CSE-induced upregulation of IL- 8 and TNF- $\alpha$ and increased IL-10 expression in BEAS-2B cells in vitro. Furthermore, icariin (40 and $80 \mu \mathrm{M})$ were more effective than DEX.
The expression and activity of proteases and anti-proteases are critical factors in the remodelling and development of COPD $(8,60,61)$. MMP9, a zinc-dependent endopeptidase, is a biomarker for COPD as it is not produced in normal lung tissues, but is produced in alveolar type II, endothelial and epithelial cells in COPD (62-64). MMPs form a group of neutral proteinases that can be divided into three subgroups (65): collagenases (MMP-1, MMP-8 and MMP-13); stromelysins and matrilysin (MMP-3, MMP-10, MMP-11 and MMP-7); and type IV collagenases (MMP-2 and MMP-9). MMP9 specifically degrade basement membrane type IV collagen. Also, type $\mathrm{V}$ collagen as well as elastin can serve as minor substrates for MMP9 (66). LeBert et al (67) found that the depletion of MMP9 partially rescued the disordered collagen fibres by using second-harmonic generation imaging technology. By modifying collagen and elastin, MMP9 has a role in numerous pathological processes such as remodelling, extracellular matrix deposition and inflammation $(62,63)$. Serum and 
A

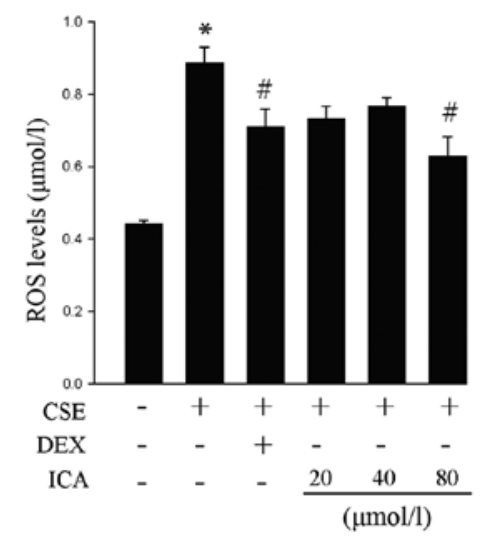

B

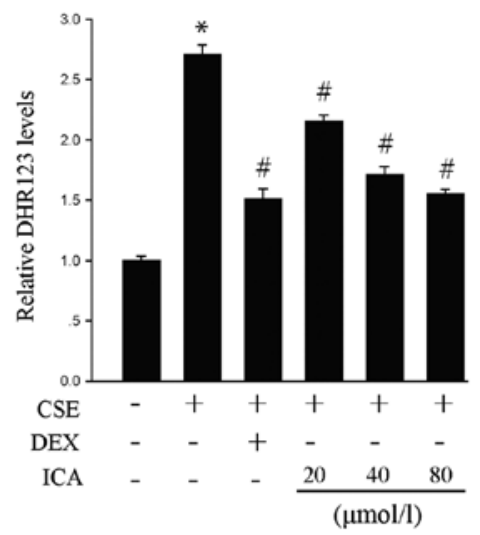

C
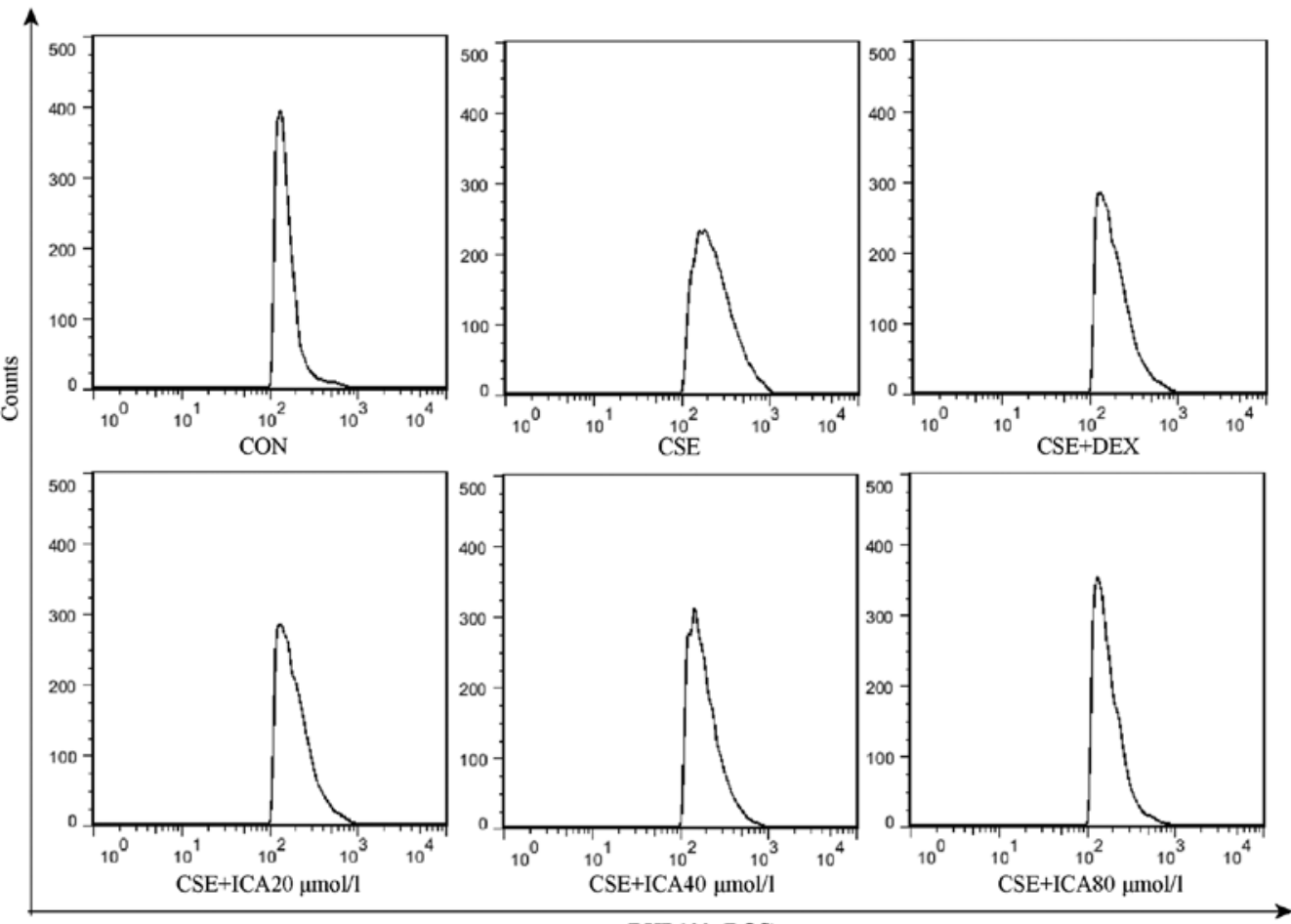

D

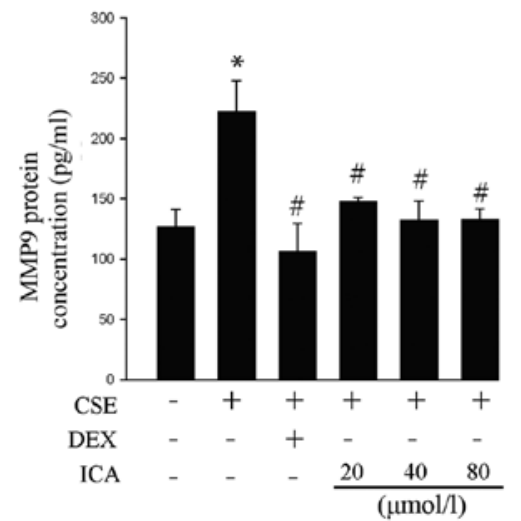

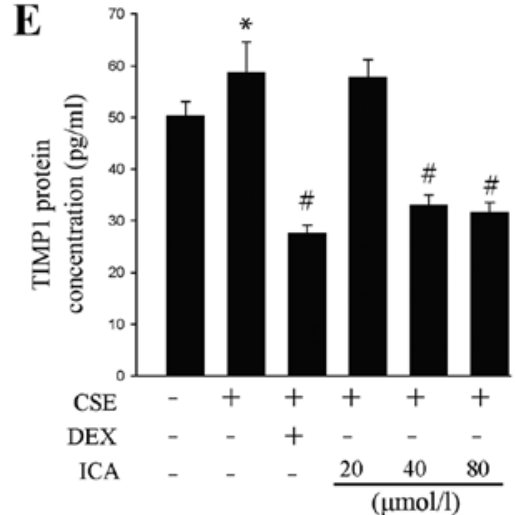

Figure 3. Effects of icariin on CSE-induced ROS production and remodelling marker secretion. BEAS-2B cells were pre-treated with 20,40 and $80 \mu \mathrm{M}$ icariin, $10 \mu \mathrm{M}$ DEX or vehicle for $24 \mathrm{~h}$, then treated with 5\% CSE for $4 \mathrm{~h}$. (A) ROS levels were detected using a human intracellular ROS assay kit. (B) DHR123 levels were detected with flow cytometry. (C) representative flow cytometry plots for the DHR123 analysis. ELISA analysis of the remodelling-related factors (D) MMP9 and (E) TIMP1. Data are expressed as the mean \pm standard deviation $(\mathrm{n}=6)$. ${ }^{*} \mathrm{P}<0.05$ vs. vehicle and ${ }^{\#} \mathrm{P}<0.05$ vs. CSE. CSE, cigarette smoke extract; ROS, reactive oxygen species; DEX, dexamethasone; ICA, icariin; MMP9, matrix metalloprotease 9; TIMP1, tissue inhibitor of metalloproteinase 1; DHR123, dihydrogenrhodamine 123 .

sputum MMP9 levels correlate with COPD severity and significant clinical symptoms such as productive cough and a low
FEV1 $(68,69)$. TIMPs are tissue inhibitors of MMPs that act as multifunctional proteins to regulate cell matrix renewal and 

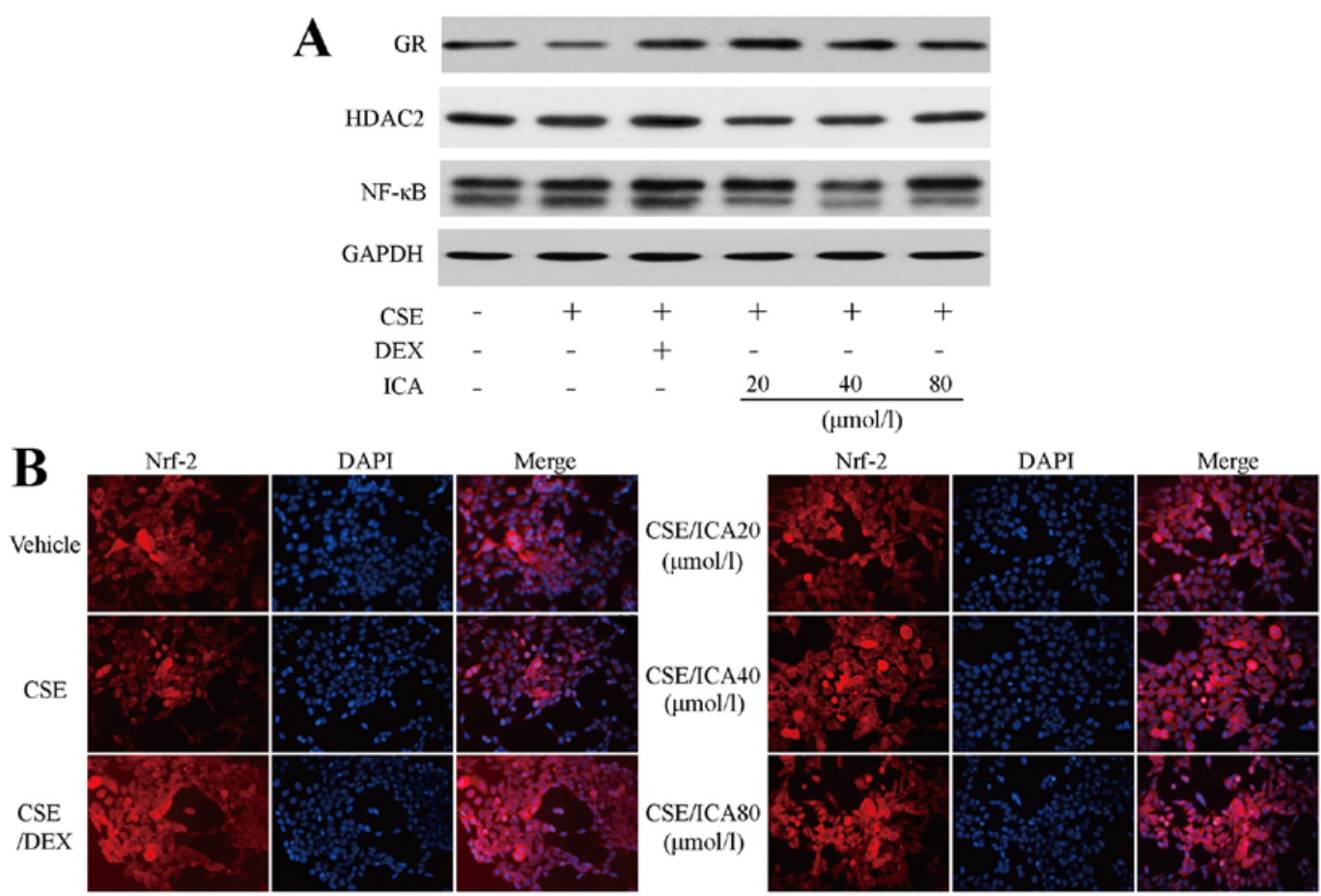

C

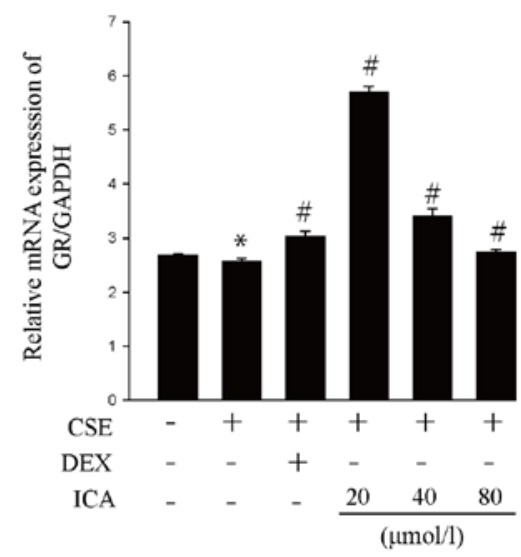

$\mathbf{E}$

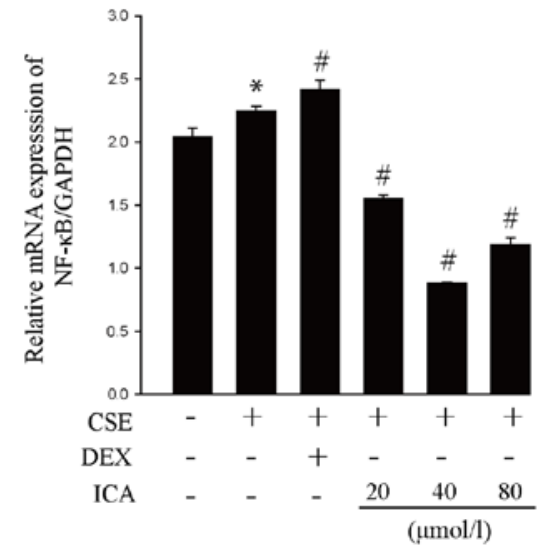

D

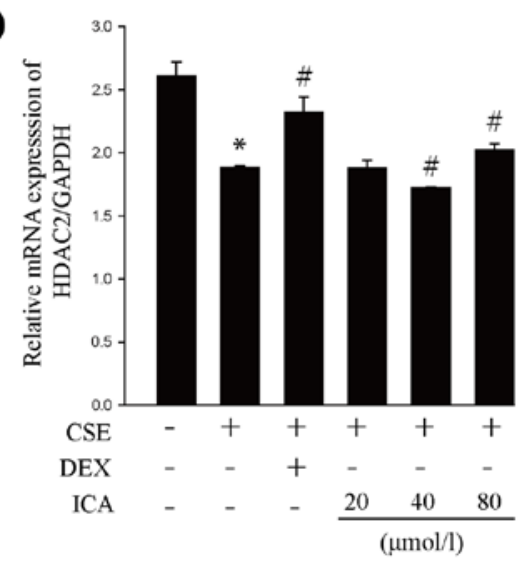

$\mathbf{F}$

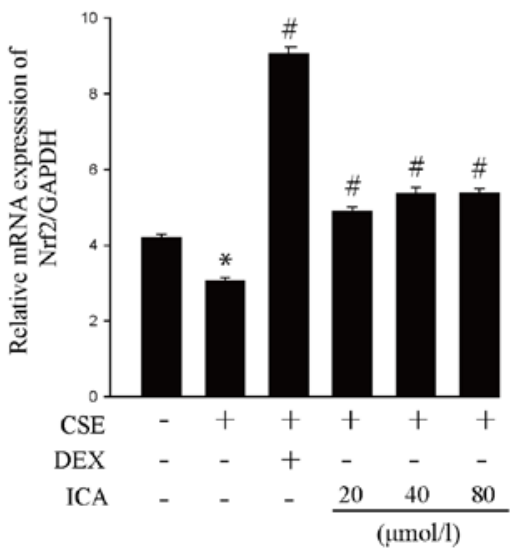

Figure 4. Effects of icariin treatment on glucocorticoid resistance-related factors. BEAS-2B cells were pre-treated with 20,40 and $80 \mu \mathrm{M}$ icariin, $10 \mu \mathrm{M}$ DEX or vehicle for $24 \mathrm{~h}$, then treated with 5\% CSE for $4 \mathrm{~h}$. (A) Western blotting analysis of GR, HDAC2 and NF-kB protein expression. (B) Nrf2 immunofluorescence (red) in BEAS-2B cells (x40 magnification). Reverse transcription-quantitative PCR analysis of (C) GR, (D) HDAC2, (E) NF- $\kappa$ B and (F) Nrf2 mRNA expression. Data are expressed as means $\pm \mathrm{SD}(\mathrm{n}=6)$. Western blotting and immunofluorescence staining were performed 3 times. "P<0.05 vs. vehicle and ${ }^{\sharp} \mathrm{P}<0.05$ vs. CSE. DEX, dexamethasone; CSE, cigarette smoke extract; GR, glucocorticoid receptor; HDAC2, histone deacetylase 2; Nrf2, erythroid 2 like 2; CSE, cigarette smoke extract; DEX, dexamethasone; ICA, icariin.

cell activity (70-72). Studies have shown that TIMP1 specifically inhibits the activity of MMP9 $(8,37,73)$. The present study revealed a significant increase in MMP9 expression and an adaptive decline in TIMP1 expression in CSE-exposed 
BEAS-2B cells. Icariin significantly decreased MMP9 expression and increased TIMP1 expression, suggesting that icariin may serve a protective role in CSE-induced remodelling.

Preclinical studies and clinical trials have revealed that an imbalance in oxidant/antioxidant factors in patients with COPD is due to long-term exposure to cigarette smoke, which results in the production of high concentrations of ROS $(74,75)$. This imbalance plays a vital role in promoting airway remodelling and inflammation (76). ROS are implicated in the progression of COPD and increased ROS generation has been documented in patients with COPD $(75,77)$. Increased ROS may lead to epithelial cell injury and death, protease/antiprotease activity imbalance and mucus hypersecretion $(75,77)$. The present study revealed that CSE exposure significantly increased the level of ROS in BEAS-2B cells, which was then decreased following icariin treatment. Therefore, the protective effects of icariin against CSE-induced damage may be partly due to a decrease in the production of ROS.

Taken together, the results obtained in the present study revealed that icariin protected BEAS-2B against CSE-induced cell damage by decreasing the pro-inflammation/anti-inflammation imbalance, oxidative damage and airway remodelling. Furthermore, the effects of icariin on GC resistance were investigated as GCs exert a significant anti-inflammatory effect, but this effect is reduced in patients with COPD due to GC resistance $(19,20,78)$. GCs enter the cytoplasm to form a complex with GRs, which is then transferred to the nucleus and acetylated. The complex subsequently binds to the GR response element and leads to the transcription of hormone-sensitive genes. HDAC2 deacetylates the acetylated GC-GR complex and competitively binds to NF- $\kappa B$ to reduce acetylation of NF- $\kappa \mathrm{B}$, thereby decreasing the release of inflammatory factors such as IL- 8 and TNF- $\alpha$. The dynamic transformation of acetylation and deacetylation of GRs in the nucleus is closely associated with transcription of inflammatory factors. Therefore, primary GC resistance in patients with COPD may be attributed to the lack of HDAC2 in cells $(19,79,80)$. Additionally, HDAC2 is involved in GR-mediated gene transcriptional repression through the deacetylation of the GR-GC complex $(21,78)$. Numerous studies have shown that activation of Nrf2 may be involved in GC resistance by enhancing the activity of HDAC2 $(81,82)$. The present study revealed that CSE-exposed BEAS-2B cells expressed low levels of GR mRNA and protein, while pre-treatment with icariin rescued GR expression. Furthermore, HDAC2 expression, which drives the GR to compete with Nrf2 following GR deacetylation, was also increased by icariin, and Nrf2 expression, which regulates HDAC2 activity, was correspondingly elevated. By contrast, icariin decreased the protein and mRNA expression of NF- $\kappa$ B. These data suggested that the mechanism by which icariin protected against CSE-induced cell injury may be attributed to the reversal of $\mathrm{GC}$ resistance.

In conclusion, the present study revealed that icariin exerted anti-inflammatory, antioxidative and anti-remodelling effects in CSE-induced cell damage, potentially by reversing GC resistance. The results are consistent with those reported in a previous study, in which icariin alleviated CSE-induced inflammatory responses by normalizing GR expression and decreasing NF- $\mathrm{\kappa B}$ expression in vivo and in vitro (83). Furthermore, icariin was revealed to serve a protective role against CSE-mediated oxidative stress in the human lung epithelial cell line A549 by quenching ROS and upregulating glutathione via a PI3K/AKT/Nrf2-dependent mechanism (32). However, the clinical application of icariin in COPD and other GC-resistant diseases requires further investigation.

\section{Acknowledgements}

Not applicable.

\section{Funding}

This project was supported by funding from the National Natural Science Foundation of China (grant no. 81302931 to HYZ, grant no. 81703829 to JS, grant no. 81573758 to JCD and grant no. 81603406 to FL).

\section{Availability of data and materials}

The datasets used and/or analyzed during the current study are available from the corresponding author on reasonable request.

\section{Authors' contributions}

HZ and JS designed the study. LH, FL, LL, LZ, CY, QL , JQ and JD performed the laboratory experiments. LH and FL performed the statistical analysis and drafted the manuscript. HZ, JS and JD made significant conceptual contributions to the manuscript. HZ, JS and JD reviewed the final version of the paper. All the authors provided intellectual content and approved the final version of the manuscript.

\section{Ethics approval and consent to participate}

The present study was approved by The Affiliated Huashan Hospital of Fudan University (Shanghai, China).

\section{Patient consent for publication}

Not applicable.

\section{Competing interests}

The authors declare that they have no competing interests.

\section{References}

1. Mathers CD and Loncar D: Projections of global mortality and burden of disease from 2002 to 2030. PLoS Med 3: e442, 2006.

2. Hanania NA and Marciniuk DD: A unified front against COPD: Clinical practice guidelines from the American College of Physicians, the American College of Chest Physicians, the American Thoracic Society, and the European Respiratory Society. Chest 140: 565-566, 2011.

3. Rabe KF, Hurd S, Anzueto A, Barnes PJ, Buist SA, Calverley P, Fukuchi Y, Jenkins C, Rodriguez-Roisin R, van Weel C, et al: Global strategy for the diagnosis, management, and prevention of chronic obstructive pulmonary disease: GOLD executive summary. Am J Respir Crit Care Med 176: 532-555, 2007.

4. Aghapour M, Raee P, Moghaddam SJ, Hiemstra PS and Heijink IH: Airway epithelial barrier dysfunction in chronic obstructive pulmonary disease: Role of cigarette smoke exposure. Am J Respir Cell Mol Biol 58: 157-169, 2018. 
5. Ng DS, Liao W, Tan WS, Chan TK, Loh XY and Wong WS Anti-malarial drug artesunate protects against cigarette smoke-induced lung injury in mice. Phytomedicine 21: $1638-1644,2014$

6. Murray LA, Dunmore R, Camelo A, Da Silva CA, Gustavsson MJ, Habiel DM, Hackett TL, Hogaboam CM, Sleeman MA and Knight DA: Acute cigarette smoke exposure activates apoptotic and inflammatory programs but a second stimulus is required to induce epithelial to mesenchymal transition in COPD epithelium. Respir Res 18: 82, 2017

7. Huang AX, Lu LW, Liu WJ and Huang M: Plasma inflammatory cytokine IL-4, IL-8, IL-10, and TNF- $\alpha$ levels correlate with pulmonary function in patients with asthma-chronic obstructive pulmonary disease (COPD) overlap syndrome. Med Sci Monit 22: 2800-2808, 2016.

8. Wang C, Li Z, Liu X, Peng Q, Li F, Li D and Wang C: Effect of Liuweibuqi capsule, a Chinese patent medicine, on the JAK1/STAT3 pathway and MMP9/TIMP1 in a chronic obstructive pulmonary disease rat model. J Tradit Chin Med 35: 54-62, 2015.

9. Marushchak M, Maksiv K and Krynytska I: The specific features of free radical oxidation in patients with chronic obstructive pulmonary disease and arterial hypertension. Pol Merkur Lekarski 47: 95-98, 2019

10. Bateman ED, Hurd SS, Barnes PJ, Bousquet J, Drazen JM, FitzGerald JM, Gibson P, Ohta K, O'Byrne P, Pedersen SE, et al: Global strategy for asthma management and prevention: GINA executive summary. Eur Respir J 31: 143-178, 2008.

11. Barnes PJ, Greening AP and Crompton GK: Glucocorticoid resistance in asthma. Am J Respir Crit Care Med 152 (Suppl): S125-S140, 1995.

12. Burmester GR and Pope JE: Novel treatment strategies in rheumatoid arthritis. Lancet 389: 2338-2348, 2017.

13. Baumgart DC and Sandborn WJ: Inflammatory bowel disease: Clinical aspects and established and evolving therapies. Lancet 369: 1641-1657, 2007.

14. Torres J, Mehandru S, Colombel JF and Peyrin-Biroulet L: Crohn's disease. Lancet 389: 1741-1755, 2017.

15. Dignass A, Van Assche G, Lindsay JO, Lémann M, Söderholm J, Colombel JF, Danese S, D'Hoore A, Gassull M, Gomollón F, et al: The second European evidence-based Consensus on the diagnosis and management of Crohn's disease: Current management J Crohn's Colitis 4: 28-62, 2010.

16. Rhen T and Cidlowski JA: Antiinflammatory action of glucocorticoids-new mechanisms for old drugs. N Engl J Med 353: 1711-1723, 2005.

17. Barnes PJ: New therapies for chronic obstructive pulmonary disease. Med Princ Pract 19: 330-338, 2010.

18. Morjaria JB, Malerba M and Polosa R: Biologic and pharmacologic therapies in clinical development for the inflammatory response in COPD. Drug Discov Today 15: 396-405, 2010.

19. Barnes PJ: How corticosteroids control inflammation: Quintiles Prize Lecture 2005. Br J Pharmacol 148: 245-254, 2006.

20. Rodriguez JM, Monsalves-Alvarez M, Henriquez S, Llanos MN and Troncoso R: Glucocorticoid resistance in chronic diseases. Steroids 115: 182-192, 2016.

21. Barnes PJ and Adcock IM: Glucocorticoid resistance in inflammatory diseases. Lancet 373: 1905-1917, 2009.

22. Cosio BG, Tsaprouni L, Ito K, Jazrawi E, Adcock IM and Barnes PJ: Theophylline restores histone deacetylase activity and steroid responses in COPD macrophages. J Exp Med 200: 689-695, 2004

23. Barnes PJ, Ito K and Adcock IM: Corticosteroid resistance in chronic obstructive pulmonary disease: Inactivation of histone deacetylase. Lancet 363: 731-733, 2004

24. Zhou Z, Zheng W, Liang T, Yan Q, Zhang C, Huang H, Liu X and Ye X: Efficacy and safety of Chuankezhi injection in patients with chronic obstructive pulmonary disease: A systematic review and meta-analysis protocol. Medicine (Baltimore) 99: e18620, 2020.

25. Zhao YL, Song HR, Fei JX, Liang Y, Zhang BH, Liu QP, Wang J and Hu P: The effects of Chinese yam-epimedium mixture on respiratory function and quality of life in patients with chronic obstructive pulmonary disease. J Tradit Chin Med 32: 203-207, 2012.

26. He W, Sun H, Yang B, Zhang D and Kabelitz D Immunoregulatory effects of the herba Epimediia glycoside icariin. Arzneimittelforschung 45: 910-913, 1995.

27. Shi Y, Yan WH, Lin QY and Wang WM: Icariin influences cardiac remodeling following myocardial infarction by regulating the CD147/MMP-9 pathway. J Int Med Res 46: 2371-2385, 2018.
28. Dong H, Ming S, Fang J, Li Y and Liu L: Icariin ameliorates angiotensin II-induced cerebrovascular remodeling by inhibiting Nox2-containing NADPH oxidase activation. Hum Cell 32: 22-30, 2019

29. Ming LG, Chen KM and Xian CJ: Functions and action mechanisms of flavonoids genistein and icariin in regulating bone remodeling. J Cell Physiol 228: 513-521, 2013.

30. Xu CQ, Liu BJ, Wu JF, Xu YC, Duan XH, Cao YX and Dong JC: Icariin attenuates LPS-induced acute inflammatory responses: Involvement of PI3K/Akt and NF-kappaB signaling pathway. Eur J Pharmacol 642: 146-153, 2010.

31. Chen SR, Xu XZ, Wang YH, Chen JW, Xu SW, Gu LQ and Liu PQ: Icariin derivative inhibits inflammation through suppression of p38 mitogen-activated protein kinase and nuclear factor-kappaB pathways. Biol Pharm Bull 33: 1307-1313, 2010.

32. Wu J, Xu H, Wong PF, Xia S, Xu J and Dong J: Icaritin attenuates cigarette smoke-mediated oxidative stress in human lung epithelial cells via activation of PI3K-AKT and Nrf2 signaling. Food Chem Toxicol 64: 307-313, 2014

33. Krystosek A and Sachs L: Control of lysozyme induction in the differentiation of myeloid leukemic cells. Cell 9: 675-684, 1976.

34. Hu L, Yu Y, Huang H, Fan H, Hu L, Yin C, Li K, Fulton DJ and Chen F: Epigenetic regulation of interleukin 6 by histone acetylation in macrophages and its role in paraquat-induced pulmonary Fibrosis. Front Immunol 7: 696, 2017.

35. Livak KJ and Schmittgen TD: Analysis of relative gene expression data using real-time quantitative PCR and the 2(-Delta Delta C(T)) method. Methods 25: 402-408, 2001.

36. Papakonstantinou E, Karakiulakis G, Batzios S, Savic S, Roth M, Tamm M and Stolz D: Acute exacerbations of COPD are associated with significant activation of matrix metalloproteinase 9 irrespectively of airway obstruction, emphysema and infection. Respir Res 16: 78, 2015.

37. Navratilova Z, Kolek V and Petrek M: Matrix metalloproteinases and their inhibitors in chronic obstructive pulmonary disease. Arch Immunol Ther Exp (Warsz) 64: 177-193, 2016.

38. Vandewalle J, Luypaert A, De Bosscher K and Libert C: Therapeutic mechanisms of glucocorticoids. Trends Endocrinol Metab 29: 42-54, 2018.

39. Li J, Liu D, Wu J, Zhang D, Cheng B, Zhang Y, Yin Z, Wang Y, Du J and Ling C: Ginsenoside Rg1 attenuates ultraviolet $\mathrm{B}$-induced glucocortisides resistance in keratinocytes via Nrf2/HDAC2 signalling. Sci Rep 6: 39336, 2016.

40. Stabile AM, Marinucci L, Balloni S, Giuliani A, Pistilli A, Bodo $\mathrm{M}$ and Rende $\mathrm{M}$ : Long term effects of cigarette smoke extract or nicotine on nerve growth factor and its receptors in a bronchial epithelial cell line. Toxicol In Vitro 53: 29-36, 2018.

41. Munakata S, Ishimori K, Kitamura N, Ishikawa S, Takanami Y and Ito S: Oxidative stress responses in human bronchial epithelial cells exposed to cigarette smoke and vapor from tobacco- and nicotine-containing products. Regul Toxicol Pharmacol 99: 122-128, 2018.

42. Eisner MD, Anthonisen N, Coultas D, Kuenzli N, Perez-Padilla R, Postma D, Romieu I, Silverman EK and Balmes JR; Committee on Nonsmoking COPD, Environmental and Occupational Health Assembly: An official American Thoracic Society public policy statement: Novel risk factors and the global burden of chronic obstructive pulmonary disease. Am J Respir Crit Care Med 182: 693-718, 2010.

43. Lee H, Jung KH, Park S, Kil YS, Chung EY, Jang YP, Seo EK and Bae H: Inhibitory effects of Stemona tuberosa on lung inflammation in a subacute cigarette smoke-induced mouse model. BMC Complement Altern Med 14: 513, 2014.

44. Ramos CO, Campos KKD, Costa GP, Cangussú SD, Talvani A and Bezerra FS: Taurine treatment decreases inflammation and oxidative stress in lungs of adult mice exposed to cigarette smoke. Regul Toxicol Pharmacol 98: 50-57, 2018.

45. Chen L, Ge Q, Tjin G, Alkhouri H, Deng L, Brandsma CA, Adcock I, Timens W, Postma D, Burgess JK, et al: Effects of cigarette smoke extract on human airway smooth muscle cells in COPD. Eur Respir J 44: 634-646, 2014.

46. BéruBé K, Aufderheide M, Breheny D, Clothier R, Combes R, Duffin R, Forbes B, Gaça M, Gray A, Hall I, et al: In vitro models of inhalation toxicity and disease. The report of a FRAME workshop. Altern Lab Anim 37: 89-141, 2009.

47. López-Rodríguez JC, Benedé S, Barderas R, Villalba M and Batanero E: Airway epithelium plays a leading role in the complex framework underlying respiratory allergy. J Investig Allergol Clin Immunol 27: 346-355, 2017. 
48. Gras D, Chanez P, Vachier I, Petit A and Bourdin A: Bronchial epithelium as a target for innovative treatments in asthma. Pharmacol Ther 140: 290-305, 2013.

49. Pouli AE, Hatzinikolaou DG, Piperi C, Stavridou A Psallidopoulos MC and Stavrides JC: The cytotoxic effect of volatile organic compounds of the gas phase of cigarette smoke on lung epithelial cells. Free Radic Biol Med 34: 345-355, 2003.

50. Singh S, Verma SK, Kumar S, Ahmad MK, Nischal A, Singh SK and Dixit RK: Correlation of severity of chronic obstructive pulmonary disease with potential biomarkers. Immunol Lett 196 $1-10,2018$.

51. Zhang X, Zheng H, Zhang H, Ma W, Wang F, Liu C and He S: Increased interleukin (IL)-8 and decreased IL-17 production in chronic obstructive pulmonary disease (COPD) provoked by cigarette smoke. Cytokine 56: 717-725, 2011

52. Schneider D, Ganesan S, Comstock AT, Meldrum CA, Mahidhara R, Goldsmith AM, Curtis JL, Martinez FJ, Hershenson MB and Sajjan U: Increased cytokine response of rhinovirus-infected airway epithelial cells in chronic obstructive pulmonary disease. Am J Respir Crit Care Med 182: 332-340, 2010.

53. de Godoy I, Donahoe M, Calhoun WJ, Mancino J and Rogers RM: Elevated TNF-alpha production by peripheral blood monocytes of weight-losing COPD patients. Am J Respir Crit Care Med 153: 633-637, 1996.

54. Xie J, Yang XY, Shi JD, Deng XQ and Long W: A new inflammation marker of chronic obstructive pulmonary disease-adiponectin. World J Emerg Med 1: 190-195, 2010.

55. Barnes PJ: Therapy of chronic obstructive pulmonary disease. Pharmacol Ther 97: 87-94, 2003.

56. Wu H, Yang S, Wu X, Zhao J, Zhao J, Ning Q, Xu Y and Xie J: Interleukin-33/ST2 signaling promotes production of interleukin-6 and interleukin-8 in systemic inflammation in cigarette smoke-induced chronic obstructive pulmonary disease mice. Biochem Biophys Res Commun 450: 110-116, 2014

57. Malaviya R, Laskin JD and Laskin DL: Anti-TNFa therapy in inflammatory lung diseases. Pharmacol Ther 180: 90-98, 2017.

58. Zhang L, Cheng Z, Liu W and Wu K: Expression of interleukin (IL)-10, IL-17A and IL-22 in serum and sputum of stable chronic obstructive pulmonary disease patients. COPD 10: 459-465, 2013.

59. Pelegrino NR, Tanni SE, Amaral RA, Angeleli AY, Correa C and Godoy I: Effects of active smoking on airway and systemic inflammation profiles in patients with chronic obstructive pulmonary disease. Am J Med Sci 345: 440-445, 2013.

60. Mercer PF, Shute JK, Bhowmik A, Donaldson GC, Wedzicha JA and Warner JA: MMP-9, TIMP-1 and inflammatory cells in sputum from COPD patients during exacerbation. Respir Res 6 : $151,2005$.

61. Yao H, Hwang JW, Sundar IK, Friedman AE, McBurney MW, Guarente L, Gu W, Kinnula VL and Rahman I: SIRT1 redresses the imbalance of tissue inhibitor of matrix metalloproteinase-1 and matrix metalloproteinase-9 in the development of mouse emphysema and human COPD. Am J Physiol Lung Cell Mol Physiol 305: L615-L624, 2013.

62. Greenlee KJ, Werb Z and Kheradmand F: Matrix metalloproteinases in lung: Multiple, multifarious, and multifaceted. Physiol Rev 87: 69-98, 2007.

63. Tiede SL, Wassenberg M, Christ K, Schermuly RT, Seeger W, Grimminger F, Ghofrani HA and Gall H: Biomarkers of tissue remodeling predict survival in patients with pulmonary hypertension. Int J Cardiol 223: 821-826, 2016.

64. Vogel ER, Britt RD Jr, Faksh A, Kuipers I, Pandya H, Prakash YS, Martin RJ and Pabelick CM: Moderate hyperoxia induces extracellular matrix remodeling by human fetal airway smooth muscle cells. Pediatr Res 81: 376-383, 2017.

65. MacDougall JR and Matrisian LM: Contributions of tumor and stromal matrix metalloproteinases to tumor progression, invasion and metastasis. Cancer Metastasis Rev 14: 351-362, 1995.
66. Yao PM, Buhler JM, d'Ortho MP, Lebargy F, Delclaux C, Harf A and Lafuma C: Expression of matrix metalloproteinase gelatinases $\mathrm{A}$ and $\mathrm{B}$ by cultured epithelial cells from human bronchial explants. J Biol Chem 271: 15580-15589, 1996.

67. LeBert DC, Squirrell JM, Rindy J, Broadbridge E, Lui Y, Zakrzewska A, Eliceiri KW, Meijer AH and Huttenlocher A: Matrix metalloproteinase 9 modulates collagen matrices and wound repair. Development 142: 2136-2146, 2015.

68. Linder R, Rönmark E, Pourazar J, Behndig A, Blomberg A and Lindberg A: Serum metalloproteinase-9 is related to COPD severity and symptoms-cross-sectional data from a population based cohort-study. Respir Res 16: 28, 2015.

69. Chaudhuri R, McSharry C, Spears M, Brady J, Grierson C, Messow CM, Miele G, Nocka K, MacNee W, Connell M, et al: Sputum matrix metalloproteinase-9 is associated with the degree of emphysema on computed tomography in COPD. Transl Respir Med 1: 11, 2013.

70. Lambert E, Dassé E, Haye B and Petitfrère E: TIMPs as multifacial proteins. Crit Rev Oncol Hematol 49: 187-198, 2004.

71. Toricelli M, Melo FH, Peres GB, Silva DC and Jasiulionis MG Timp1 interacts with beta-1 integrin and CD63 along melanoma genesis and confers anoikis resistance by activating PI3-K signaling pathway independently of Akt phosphorylation. Mol Cancer 12: 22, 2013.

72. Arpino V, Brock M and Gill SE: The role of TIMPs in regulation of extracellular matrix proteolysis. Matrix Biol 44-46: 247-254, 2015.

73. Mocchegiani E, Giacconi R and Costarelli L: Metalloproteases/ anti-metalloproteases imbalance in chronic obstructive pulmonary disease: Genetic factors and treatment implications. Curr Opin Pulm Med 17 (Suppl 1): S11-S19, 2011.

74. Pryor WA and Stone K: Oxidants in cigarette smoke. Radicals, hydrogen peroxide, peroxynitrate, and peroxynitrite. Ann N Y Acad Sci 686: 12-27, discussion 27-28, 1993.

75. Boukhenouna S, Wilson MA, Bahmed K and Kosmider B: Reactive oxygen species in chronic obstructive pulmonary disease. Oxid Med Cell Longev 2018: 5730395, 2018.

76. Jiang Y, Wang X and Hu D: Mitochondrial alterations during oxidative stress in chronic obstructive pulmonary disease. Int J Chron Obstruct Pulmon Dis 12: 1153-1162, 2017.

77. MacNee W: Pulmonary and systemic oxidant/antioxidant imbalance in chronic obstructive pulmonary disease. Proc Am Thorac Soc 2: 50-60, 2005.

78. Barnes PJ: Mechanisms and resistance in glucocorticoid control of inflammation. J Steroid Biochem Mol Biol 120: 76-85, 2010

79. Ingawale DK, Mandlik SK and Patel SS: An emphasis on molecular mechanisms of anti-inflammatory effects and glucocorticoid resistance. J Complement Integr Med 12: 1-13, 2015.

80. Ito K, Yamamura S, Essilfie-Quaye S, Cosio B, Ito M, Barnes PJ and Adcock IM: Histone deacetylase 2-mediated deacetylation of the glucocorticoid receptor enables NF-kappaB suppression. J Exp Med 203: 7-13, 2006.

81. Payne DN and Adcock IM: Molecular mechanisms of corticosteroid actions. Paediatr Respir Rev 2: 145-150, 2001.

82. Ogawa S, Lozach J, Benner C, Pascual G, Tangirala RK, Westin S Hoffmann A, Subramaniam S, David M, Rosenfeld MG and Glass CK: Molecular determinants of crosstalk between nuclear receptors and toll-like receptors. Cell 122: 707-721, 2005.

83. Li L, Sun J, Xu C, Zhang H, Wu J, Liu B and Dong J: Icariin ameliorates cigarette smoke induced inflammatory responses via suppression of NF- $\mathrm{KB}$ and modulation of GR in vivo and in vitro. PLoS One 9: e102345, 2014.

This work is licensed under a Creative Commons Attribution-NonCommercial-NoDerivatives 4.0 International (CC BY-NC-ND 4.0) License. 